\title{
Evaluating Performance of Utilizing Onshore Wind Turbines Specifically the Farm Turbines in Kuwait
}

\author{
Mohammed Salem Alsubai'e*, Saad Abdullah Alshatti
}

Specialist Trainer (G) in Public Authority for Applied Education and Training, University of Arab Academy for Science, Technology and Maritime Transport, EGYPT

*Corresponding Contact:

Email: gwarer205@gmail.com

\begin{abstract}
Renewable energy is considered one of the most important and clean sources; since it does not produce any type of emission or pollution. In Kuwait, the energy of wind is existing in three main locations, which are; Ras Jal Aliyah, Bubian in addition to Subiyah, where the characteristics of wind have been evaluated in this paper based on the data generated from the meteorological measurements at $10 \mathrm{~m}$ height. Also, different studies have been performed in this paper in order to analyze the impact of height on the parameters of wind energy, wind density, in addition to wind speed. Jal Aliyah location has been studied in this paper and the results shown that there is a proportional relation between the wind speed and power, where the maximum power is potential if the speed is equal to $29.1 \mathrm{~m} / \mathrm{s}$, and the maximum averaged flux of wind power is equal to $725.54 \mathrm{~W} / \mathrm{m} 2$. Where both Bubidan Island and Ras Subiyah showed the wind direction in the North-East quadrant with speed is greater than $10 \mathrm{~m} / \mathrm{s}$. But, higher polarized distribution of Jal Aliyah was in the north direction. Based on the obtained results, it can be concluded that this paper provides and suggests a proper design of the wind turbines for designers.
\end{abstract}

Key words:

Renewable Energy, Wind Energy, Ras Jal Aliyah, Bubian, Subiyah, Wind Turbines, Wind Speed

\section{INTRODUCTION}

In general, renewable energy is considered one of the most important and clean sources; since it does not produce any type of emission or pollution. The researchers nowadays are concerned in employing these sources efficiently so that the best potential energy is taken. Renewable energy technology is description for half capacity of the recent technologies that was developed for the purposes of achieving the occurred growing within energy insist throughout the recent years. Advanced technology is hydropower and wind. Increase in 
renewable Energy alternates because of the oil price; in case of high price, there will be an increase of the renewable energy share (wind and solar) within overall energy input. Consequently, the share of coal and gas will reduce, which in turns results in a lower share in renewable energy.

So due to price oil increase, wind energy is considered as an efficient substitute to produce the needed power with lower cost. The electrical energy is generated by wind turbine through converting the kinetic energy of the wind to rotational kinetic energy. Within the novel horizontal design of the wind turbine, the energy results in a rotation within in three or two blades that are placed around the rotor. Where aerodynamics force is employed in order to provide the transmission via creating a positive torque on the shaft, which is rotating due to the movement of the blades. The wind should be obtainable at the same time when energy is being created from wind turbine because the wind could not be saved to be employed later (Bai et al, 2013).

\section{Aims AND OBJECTIVES}

The aim from this paper is studying and estimating the efficiency of exploiting Onshore Wind Turbines particularly the turbines' farm in Kuwait city. To reach the aim of this paper, the following objectives should be performed:

- To evaluate the wind energy performance in Kuwait,

- To find the suitable model of Onshore Wind Turbine to efficient generation of power in Kuwait.

- To perform feasibility study that evaluate the chosen model to be compared with fossil fuels in terms of environmental impact as well as cost.

\section{Methodology}

In Kuwait city, electrical energy is regularly created using hydrocarbon fuels, which may produce all its energy demands. Actually, Kuwait is planning now to employ additional clean sources, such as; renewable energies due to the increased-demand because of the technological development to use approximately 11.5GW (Az-Zour, 2010).

Furthermore, the turbines of the wind can produce clean, reliable, sustainable as well as effective energy source with low cost. As shown in Figure 1, the power produced through wind turbines during last few years performed by Global Wind Energy Council (GWEC).

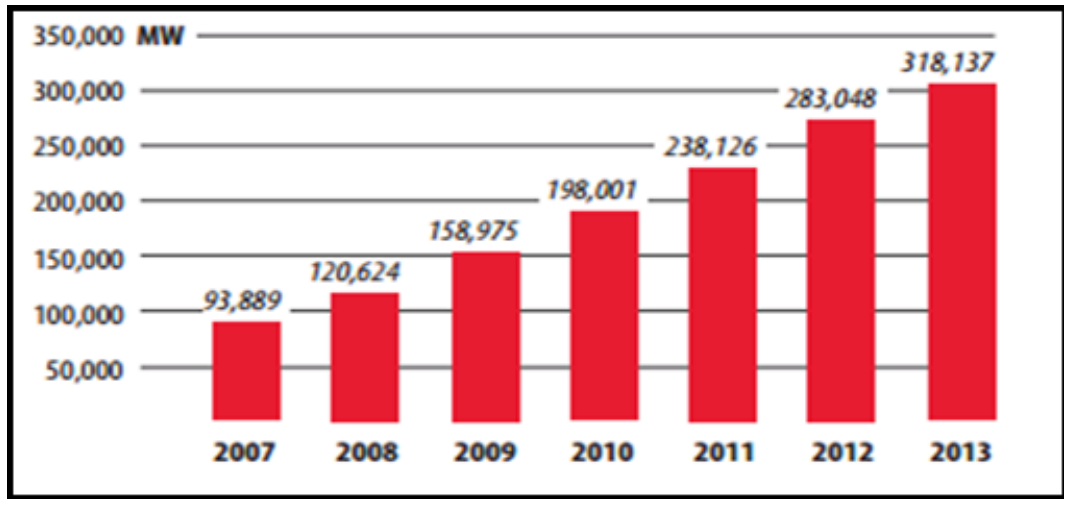

Figure 1: the capacity of wind turbines in the world (GWEC, 2013) 


\section{THE LOCATIONS OF THE STUdY}

Setting up the turbines of wind energy in Kuwait city at Mubarak Al Kabeer can be evaluated via feasibility study making for installing the wind turbines in Bubiyan Island area. The location of Bubiyan Island is shown below in Figure 2 inside the red circle and it is located in the northeast area from Kuwait.

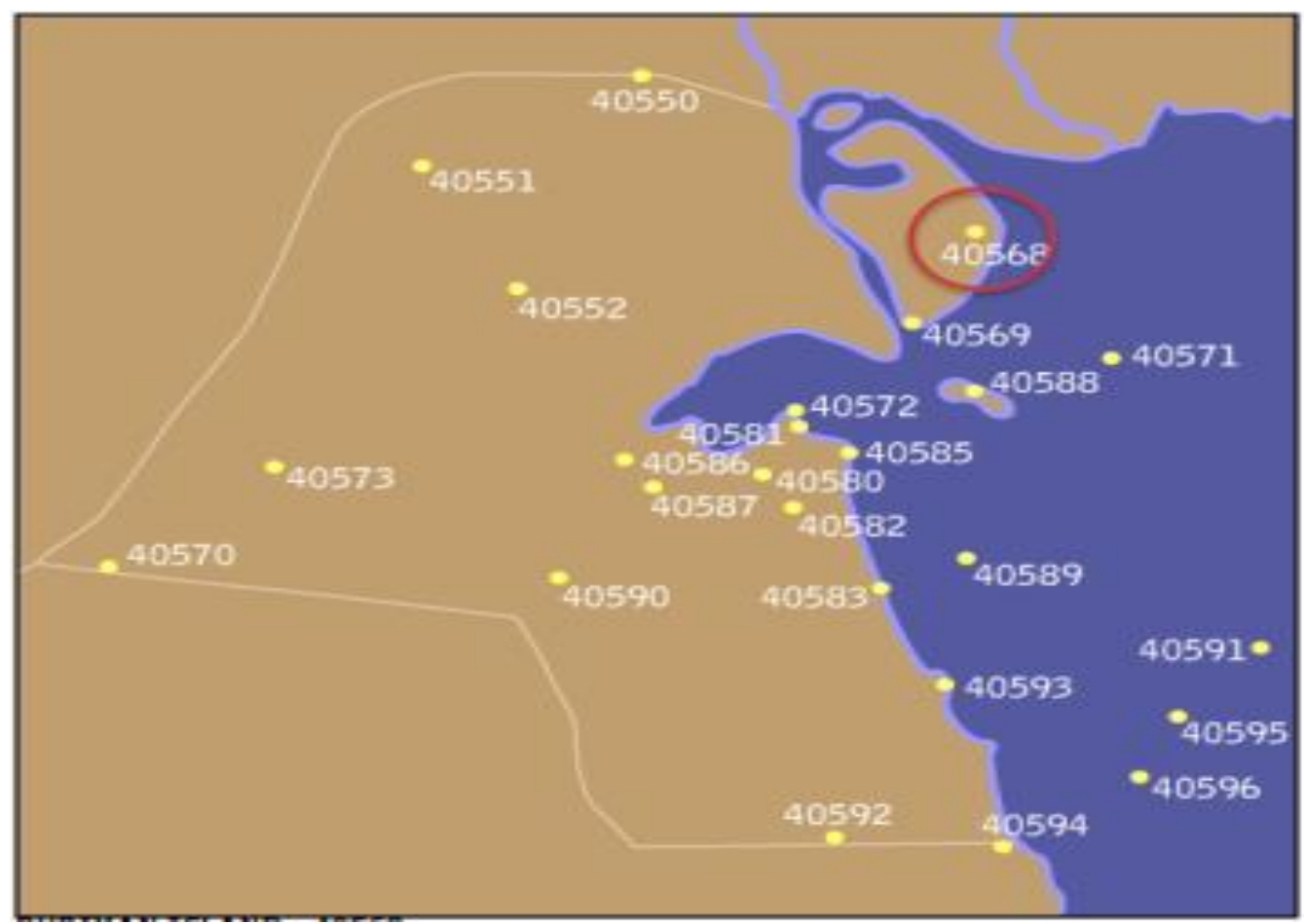

Figure 2: Bubiyan Island location

The Bubiyan Island location of is considered very active, it is placed along the coastal regions. In the morning, the flow of the wind can be estimated beside the contours, which consequences from winds within the west regions beside to southern parts.

\section{THEORY OF Wind ENERGY AND AsSESSMENT}

In Kuwait, the wind power is probable for three different and well-known situations. Table 1 includes the meteorological data for the three considered situations.

Table 1: The meteorological data for the three sites (Kuwait meteorological statistics, 2017)

\begin{tabular}{|l|l|l|l|}
\hline Site & Elevation (m) & Latitude & Longitude \\
\hline Jal Aliyah & 119.10 & $2^{\circ} 39^{\circ} 36^{\prime} 35^{\prime \prime \prime}$ & $47^{\circ} 34^{\prime} 36^{\prime \prime}$ \\
\hline RasSubyah & 1 & $29^{\circ} 34^{\prime} 24^{\prime \prime}$ & $48^{\circ} 10^{\prime} 17^{\prime \prime}$ \\
\hline Bubian Island & 4.53 & $29^{\circ} 46^{\prime} 05^{\prime \prime}$ & $48^{\circ} 22^{\prime} 29^{\prime \prime}$ \\
\hline
\end{tabular}

According to Neelamani et al, (2013) the following equation can be employed in calculating the density of the wind $\rho$ at changeable heights: 
$\rho(z)=\frac{353.05}{T} e^{-0.034(z / T)}$

Where that $\mathrm{z}$ symbolizes the height over the level of the ground. The next equation can be employed in calculating the velocity of the wind:

$V(z)=V_{r}\left(\frac{z}{z_{r}}\right)^{\alpha}$

The speed of the wind speeds is changeable with the heights. $\alpha$ denotes a factor that depends on the ground surface roughness. The magnitude for $\alpha$ equals $1 / 7$ in this case (Mathew, 2006). ' $r$ ' denotes the reference level, which is equal $10 \mathrm{~m}$ above the level of the ground. Different valued heights have been considered in this paper, which are; $30 \mathrm{~m}$ as well as $50 \mathrm{~m}$.

Equation 3 is used in order to calculate the density of the wind $(\rho)$ for diverse heights (Albadi, 2009);

$\rho(z)=\frac{353.05}{T} e^{-0.034(z / T)}$

Where that $\mathrm{T}$ refers to the Kelvin value of temperature. The obtainable wind turbine power or density of energy can be described as given below in the following equation;

$P_{I}=\frac{1}{2} * \rho * V^{3}$

Equation 5 is utilized in order to calculate the power of wind turbine if $d$ is a diameter.

$P=P_{I} * \frac{\pi \mathrm{d}^{2}}{4}$

\section{The Evaluation of the Characteristics of Wind Energy}

The following figures show the velocities and the power, which consequences for the three situations;

\section{Ras Sabah}

According to the data that have been taken each hour at heights equal to $30 \mathrm{~m}$, the estimated output power is demonstrated in Figure 3.

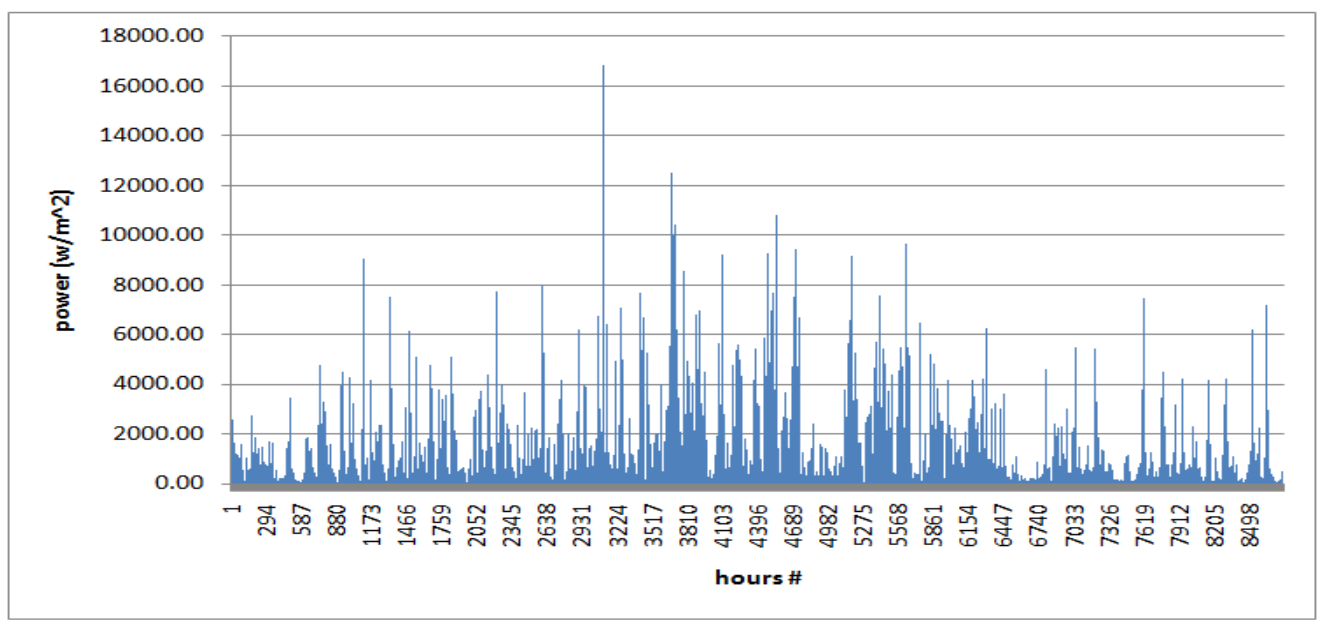

Figure 3: The histogram of the output wind power in RasSubyah obtained at 30m height 
Figure 3 illustrates the power distribution that is greater than $2000 \mathrm{w} / \mathrm{m}^{2}$; the maximum obtained of the output power value occurs in the period from June to August.

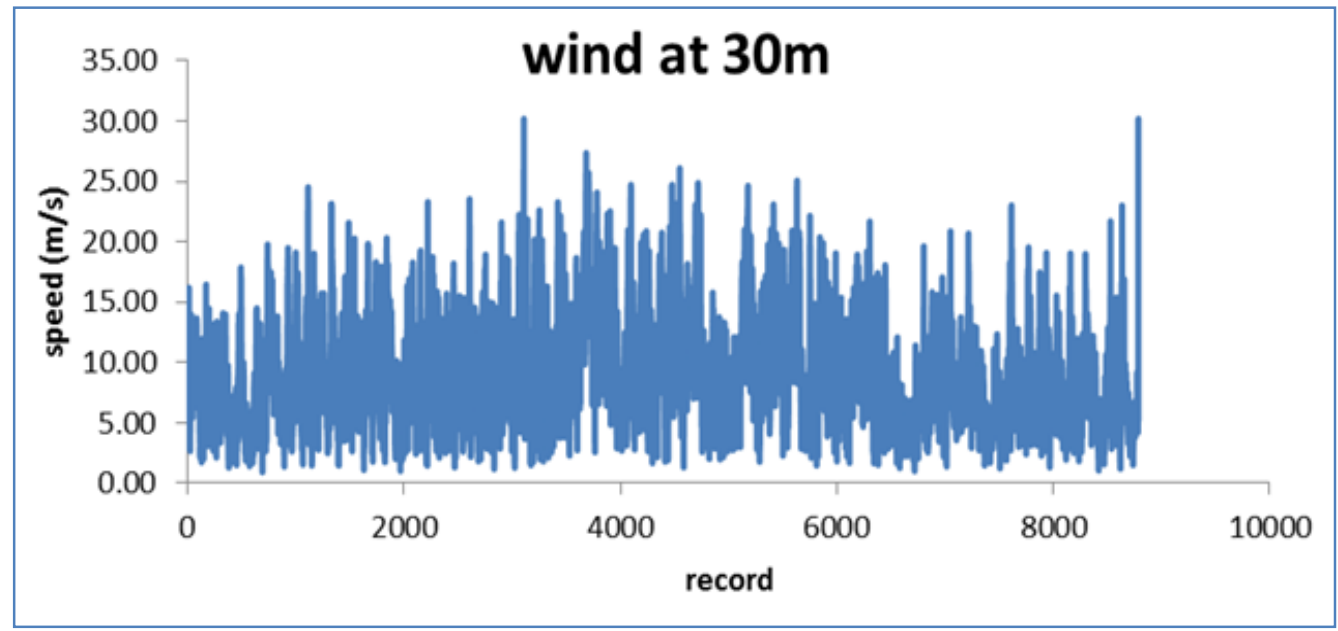

Figure 4: Wind speed at (altitude $=30 \mathrm{~m}$ )

The wind speed data has been changed at different altitudes; which are considered as typical altitudes $(30 \mathrm{~m}$ and $50 \mathrm{~m}$ ). The first study for the speed of the wind was in RasSubiyah situation, and it happens at a $30 \mathrm{~m}$ altitude above the ground level according to Figure 4 . A middle average speed is obtained at this altitude, where the highest speed $=30.2 \mathrm{~m} / \mathrm{s}$ and the lowest speed $=0.97 \mathrm{~m} / \mathrm{s}$, so the average speed was found to be $8.69 \mathrm{~m} / \mathrm{s}$.

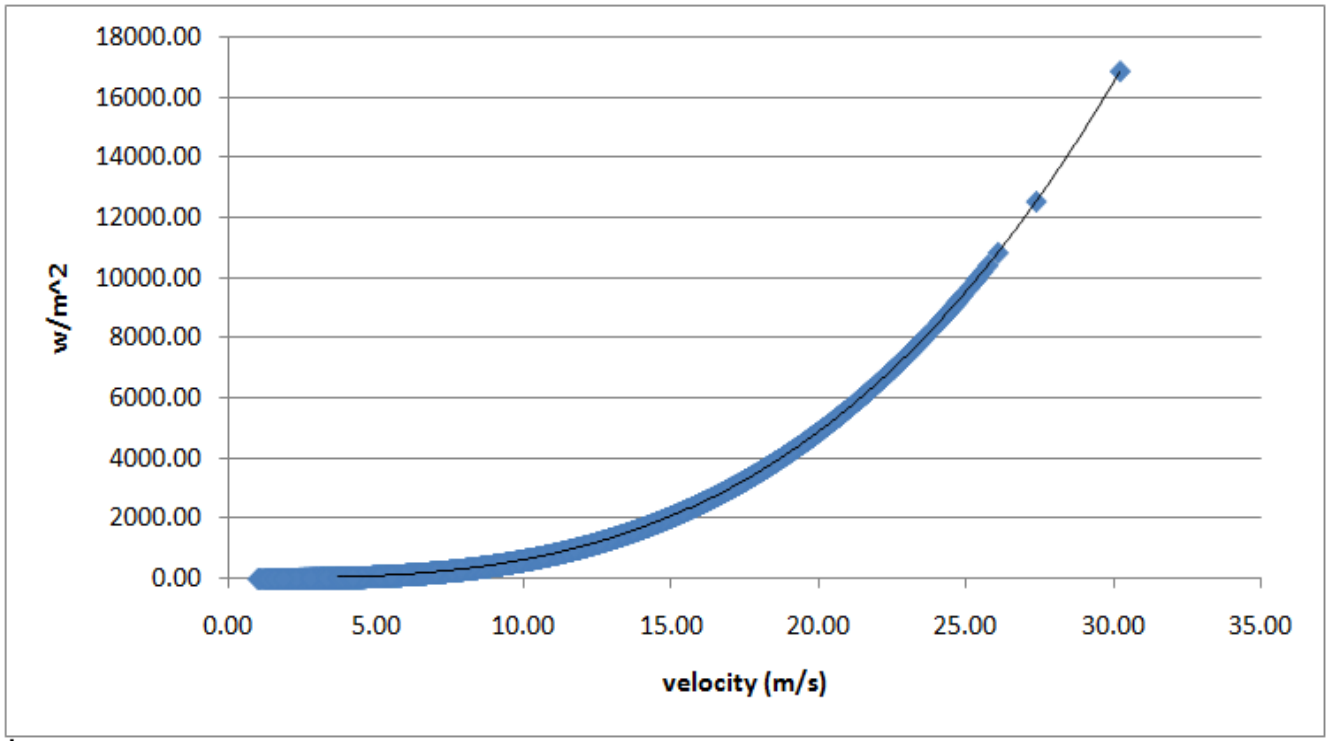

Figure 5: the generated power in RasSubyah obtained at altitude of $30 \mathrm{~m}$

As shown in Figure 5 the maximum speed is approximately equal to $30 \mathrm{~m} / \mathrm{s}$ in addition to the highest power is approximately equal to $17000 \mathrm{w} / \mathrm{m}^{2}$. Figure 6 shows the histogram of the generated power at altitude equal to $50 \mathrm{~m}$. 


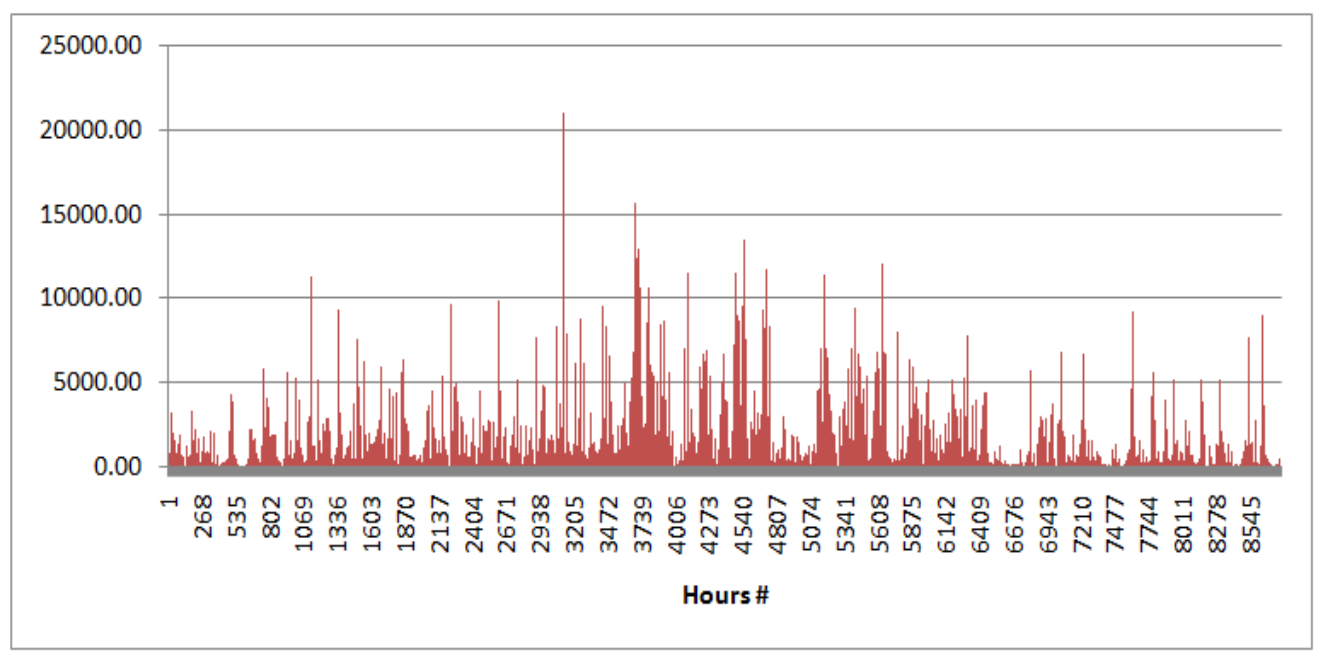

Figure 6: The histogram of the hourly wind power in RasSubyah at 50m altitude

Figure 6 illustrates that the power distribution is located over $5000 \mathrm{w} / \mathrm{m}^{2}$, the highest generated power are obtained in period from June to August. As shown in Figure 7, the maximum speed is approximately equal to $33 \mathrm{~m} / \mathrm{s}$, as well as the value of the maximum value of the power is approximately equal to $21000 \mathrm{w} / \mathrm{m}^{2}$.

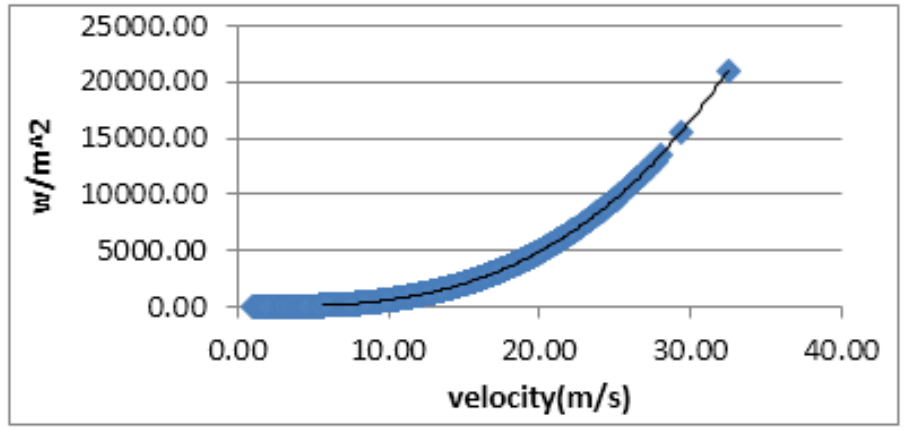

Figure 7: the output power for RasSubyah at (50 m altitude)

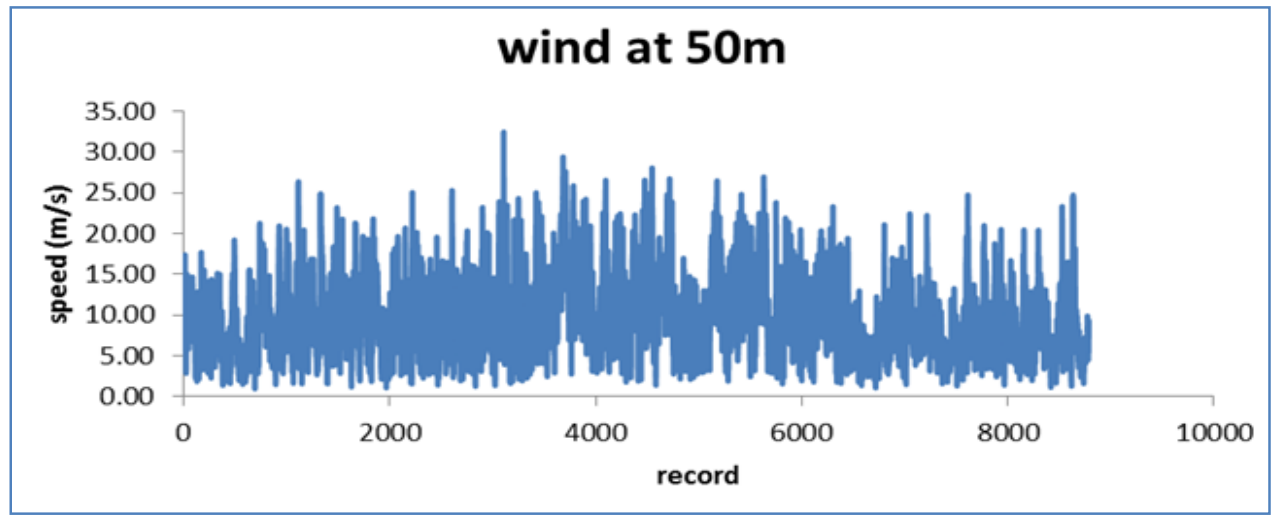

Figure 8: Wind speed at altitude $=50 \mathrm{~m}$ 
Another standard altitude were chosen is $50 \mathrm{~m}$ above the ground level in RasSubiyah. According to Figure 8, it is obvious that at $50 \mathrm{~m}$ altitude, the best result had been obtained, where the highest speed $=32.48 \mathrm{~m} / \mathrm{s}$ and the lowest speed $=1.04 \mathrm{~m} / \mathrm{s}$. Consequently, it is observed that the average speed $=9.35 \mathrm{~m} / \mathrm{s}$. It can be noticed from the available data that high speed is produced when the wind turbine is established at a high height. Therefore, it can be concluded that the speed of the wind speed increases with increasing the height above the ground level.

\section{Jalaliah}

The created power for different wind speed is calculated using equation (4), Figure 9 shows the histogram of the wind power for recorded at each hour in Jalaliah location at altitude is equal to $30 \mathrm{~m}$.

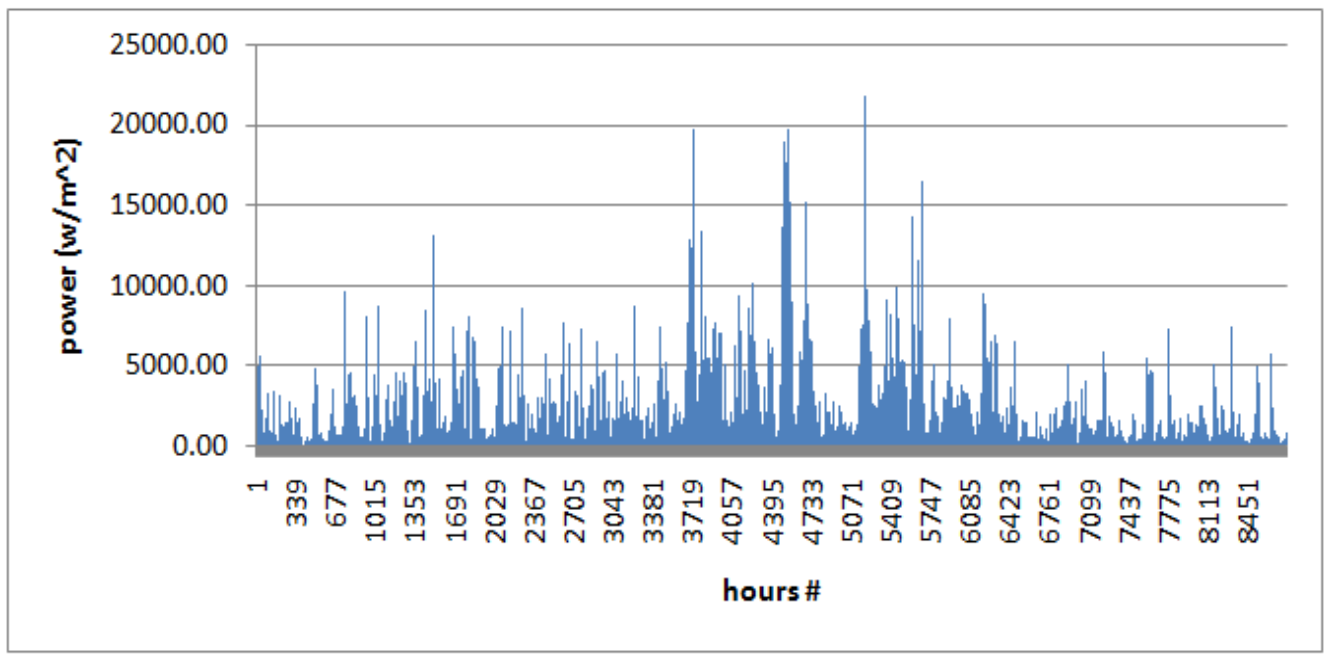

Figure 9: The generated power distribution at altitude $(30 \mathrm{~m})$ in Jalaliah

As shown in Figure 9, the situated power is above $5000 \mathrm{w} / \mathrm{m}^{2}$ and the hourly highest power is obtained between June and August. As illustrated in Figure 10 the highest speed of the wind is around $35 \mathrm{~m} / \mathrm{s}$, also the highest power magnitude is equal to $8000 \mathrm{w} / \mathrm{m}^{2}$.

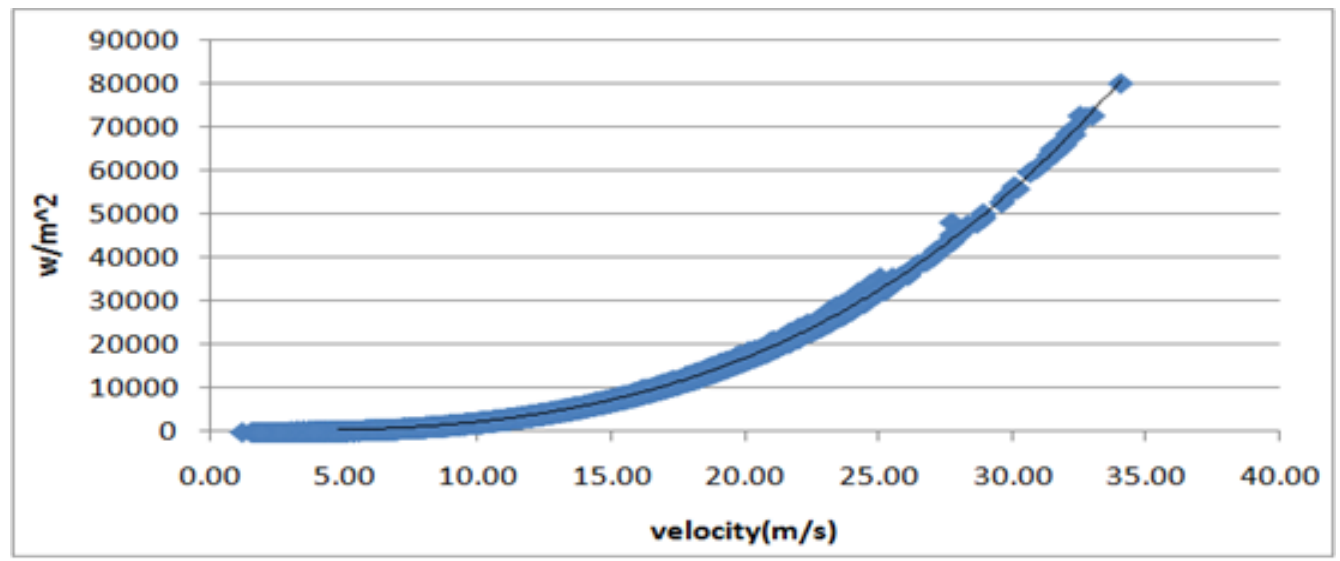

Figure 10: The output power curve at altitude equal to $30(\mathrm{~m})$ in Jalaliah 


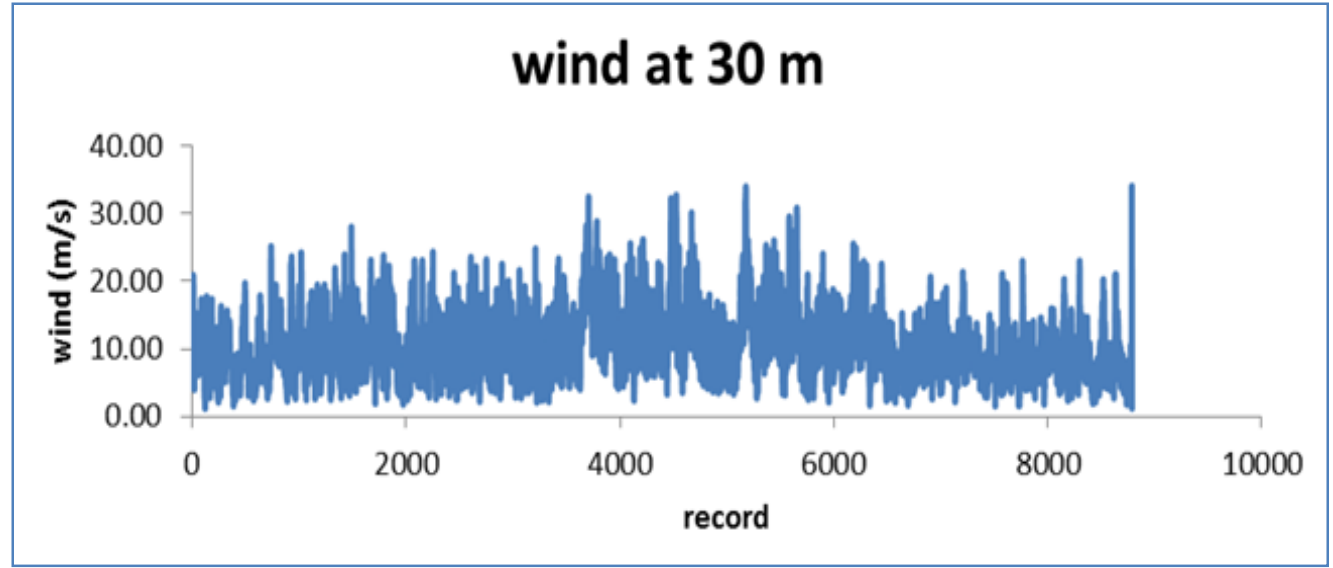

Figure 11: Wind speed at altitude $=30$ in Jalaliah

As shown in Figure 11, the first standard altitude is $30 \mathrm{~m}$ above the level of the ground where that the maximum value of speed is $34.04 \mathrm{~m} / \mathrm{s}$ and the minimum value of speed is $1.17 \mathrm{~m} / \mathrm{s}$. Consequently, the average speed $=10.42 \mathrm{~m} / \mathrm{s}$. Figure 12 shows the obtainable histogram of wind power that is recorded hourly at $(50 \mathrm{~m})$ altitude in Jalaliah.

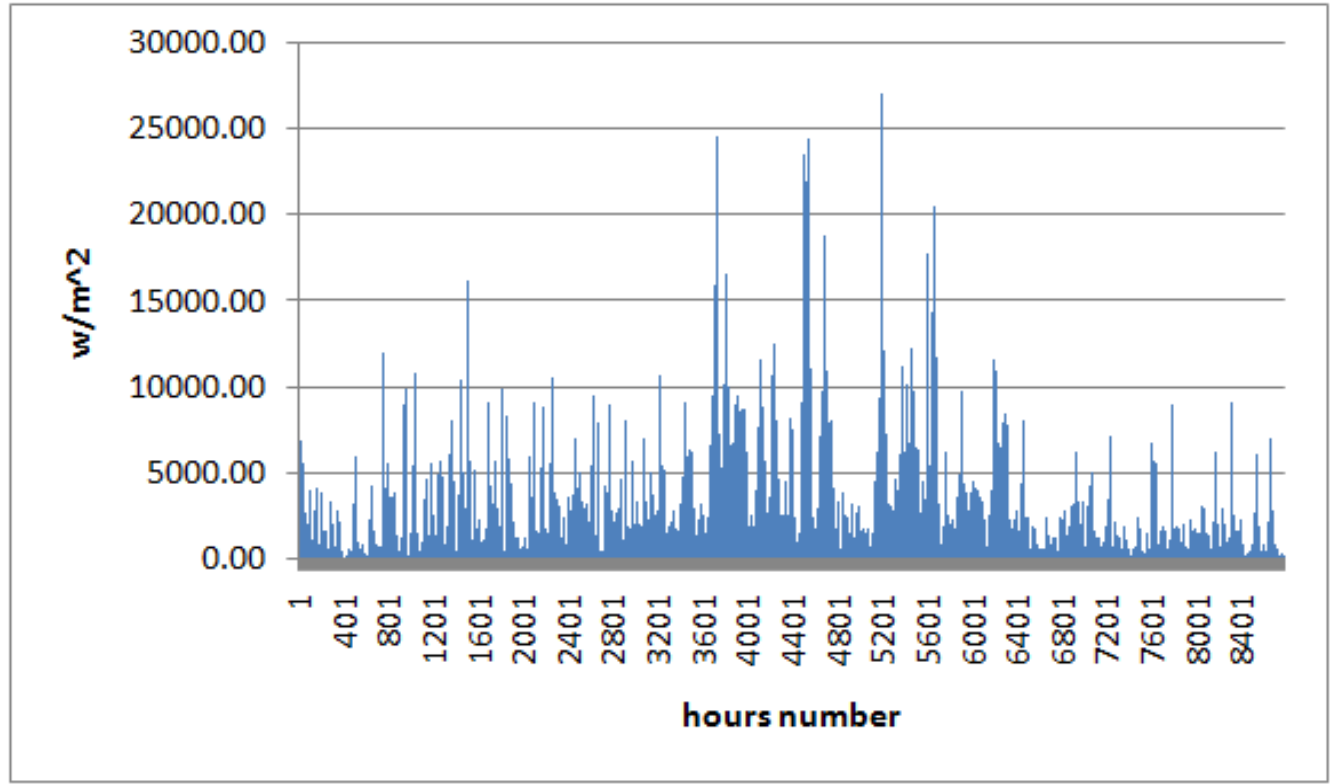

Figure 12: The histogram of the output power at altitude $(50 \mathrm{~m})$ in Jalaliah

As shown in Figure 12, the power distribution of is existed above $6 \mathrm{KW} / / \mathrm{m}^{2}$ where the maximum value of power is reached among June and August. Figure 13 shows the value of power for different velocities of the wind, where the value of the maximum speed is approximately equal to $35 \mathrm{~m} / \mathrm{s}$. 


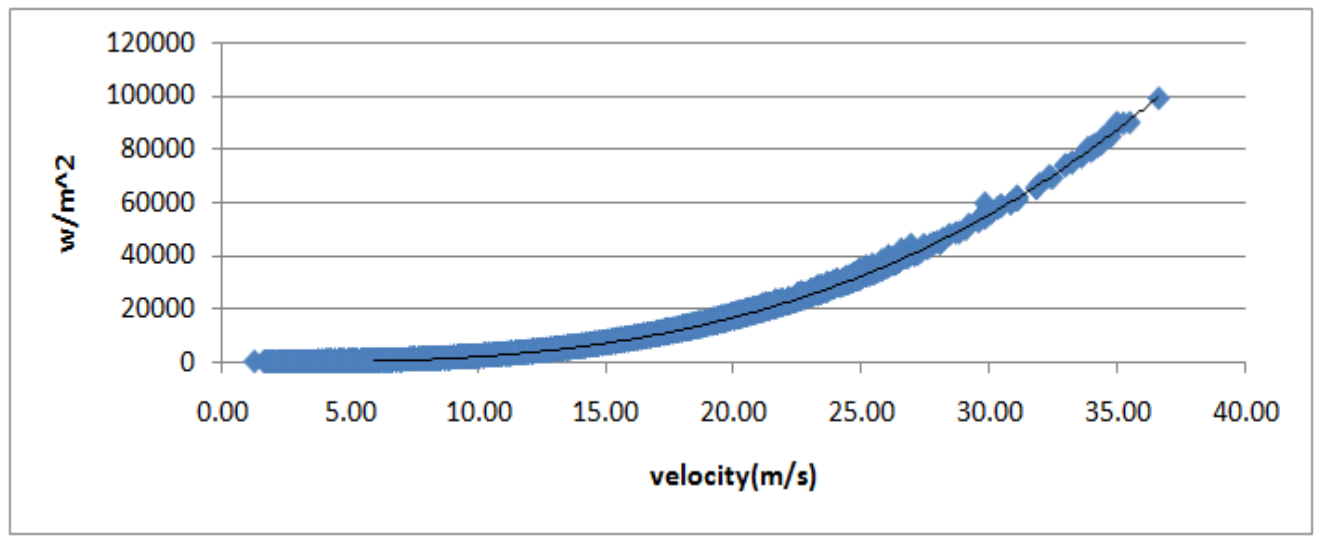

Figure 13: output power in Jalaliah at altitude equal to $50(\mathrm{~m})$

The second altitude is equal to $50 \mathrm{~m}$, where at this altitude it can be obtained the highest value for the average speed of all data. It is found that the minimum speed $=36.62 \mathrm{~m} / \mathrm{s}$ and the lowest value of speed is equal to $1.26 \mathrm{~m} / \mathrm{s}$. Consequently, the average speed is equal to $11.21 \mathrm{~m} / \mathrm{s}$. In addition, these values denotes that Jalaliah situation is the best choice in terms of the data results compared with the other two locations at the same highest.

The obtained results at these diverse altitudes were predicted because of several reasons; the speed of the wind speed increases with increasing the height. This happens due to many reasons, which are; the friction of the surface, where the houses and the trees near the ground form a barrier that let reduces the air speed.

\section{Bubian Island}

For different speed of wind, the output power is calculated through the obtainable power equations. Figure 14 shows the wind power histogram at $30 \mathrm{~m}$ altitude in Bubian location.

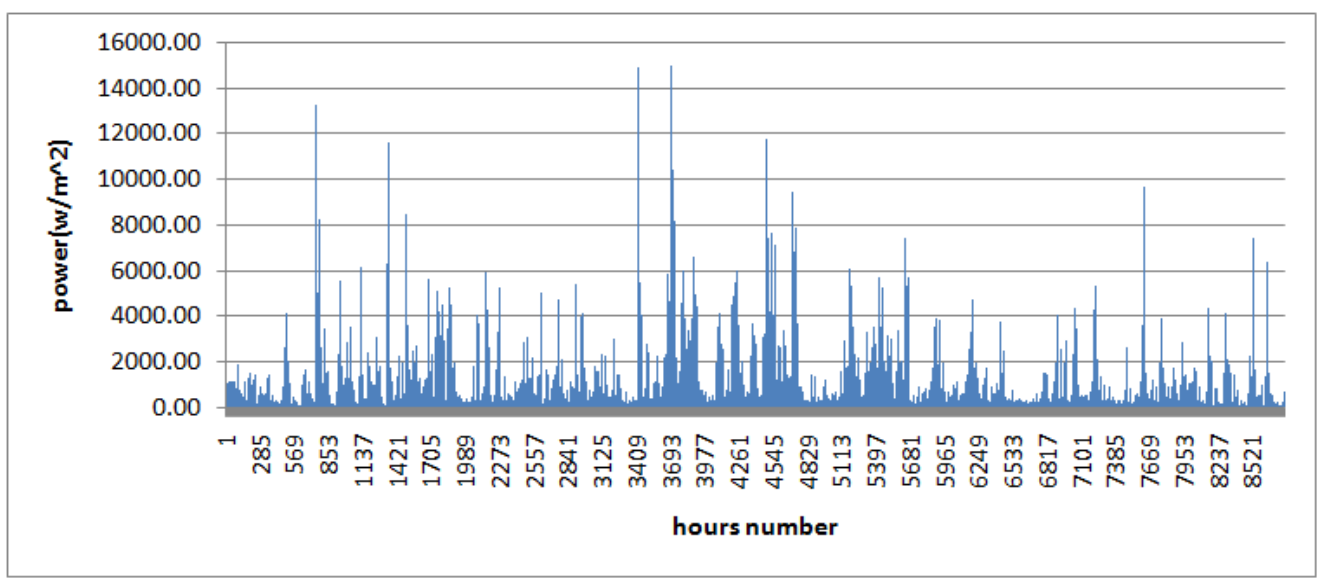

Figure 14: The output power at 30m altitude in Bubian

As shown in Figure 14, the power distribution is above $16 \mathrm{KW} / / \mathrm{m}^{2}$ and the highest output power value is obtained also form June to August. As illustrated in Figure 15 the highest speed of wind is approximately equal to $30 \mathrm{~m} / \mathrm{s}$. 


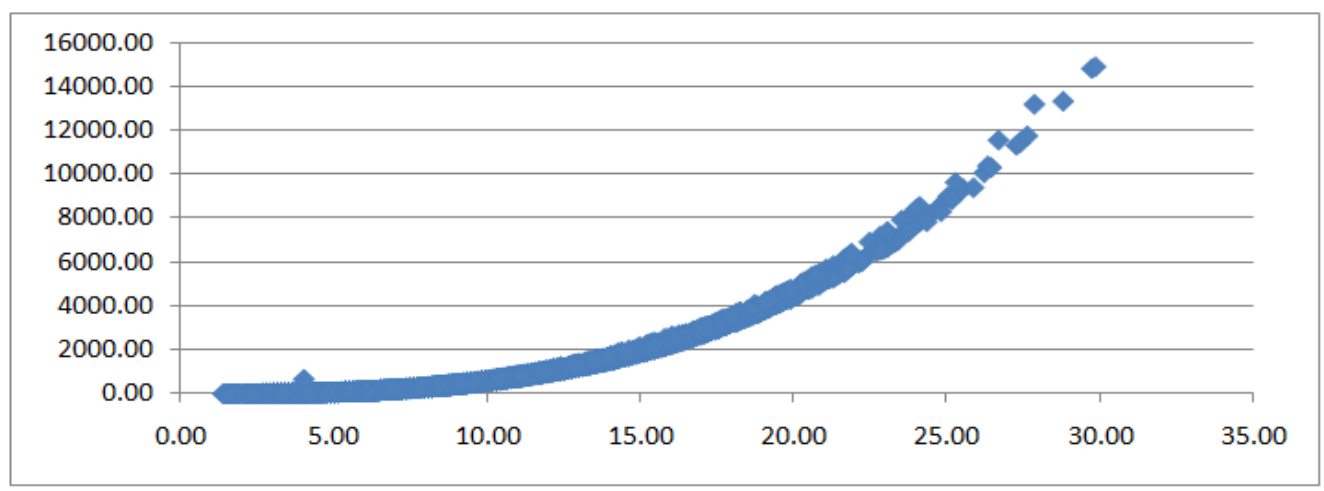

Figure 15: The output power curve in Bubian Island at altitude equal to 30 (m)

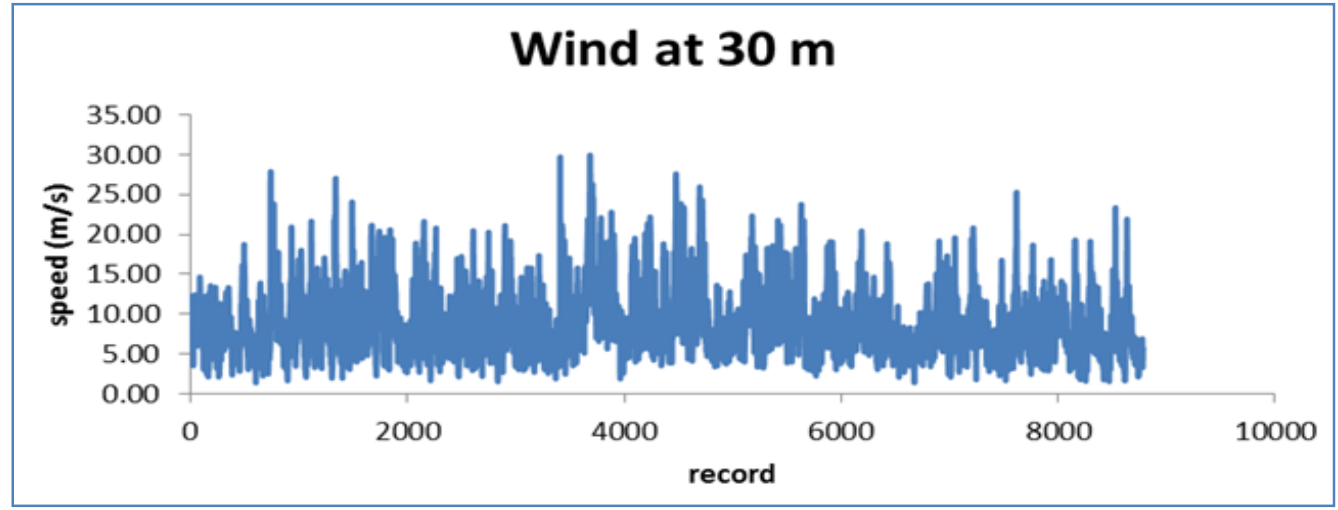

Figure 16: Wind speed at altitude $=30 \mathrm{~m}$

As illustrated in Figure 15, at altitude $30 \mathrm{~m}$, the highest speed $=28.83 \mathrm{~m} / \mathrm{s}$ and the lowest speed $=1.4 \mathrm{~m} / \mathrm{s}$. Consequently, the value of the average speed $=8.67 \mathrm{~m} / \mathrm{s}$, it's a middle result between the speed at $50 \mathrm{~m}$ and $10 \mathrm{~m}$ altitudes. Figure 17 shows the wind power curve in Bubian Island at height equal to $50(\mathrm{~m})$.

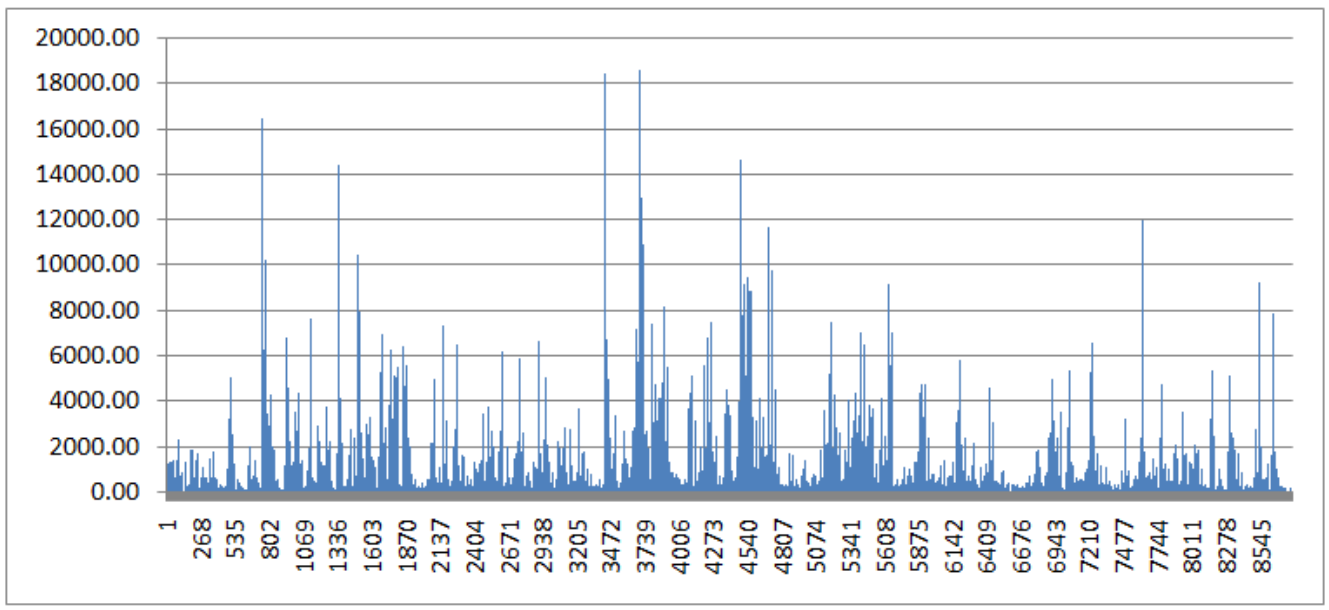

Figure 17: The distribution of output power at 30m altitude in Bubian Island 
Figure 17 explains that the power distribution is located above $2 \mathrm{KW} / / \mathrm{m}^{2}$ and the highest output power magnitude obtained also from June to August. Figure 18 shows that highest wind speed is approximately equal to $32 \mathrm{~m} / \mathrm{s}$.

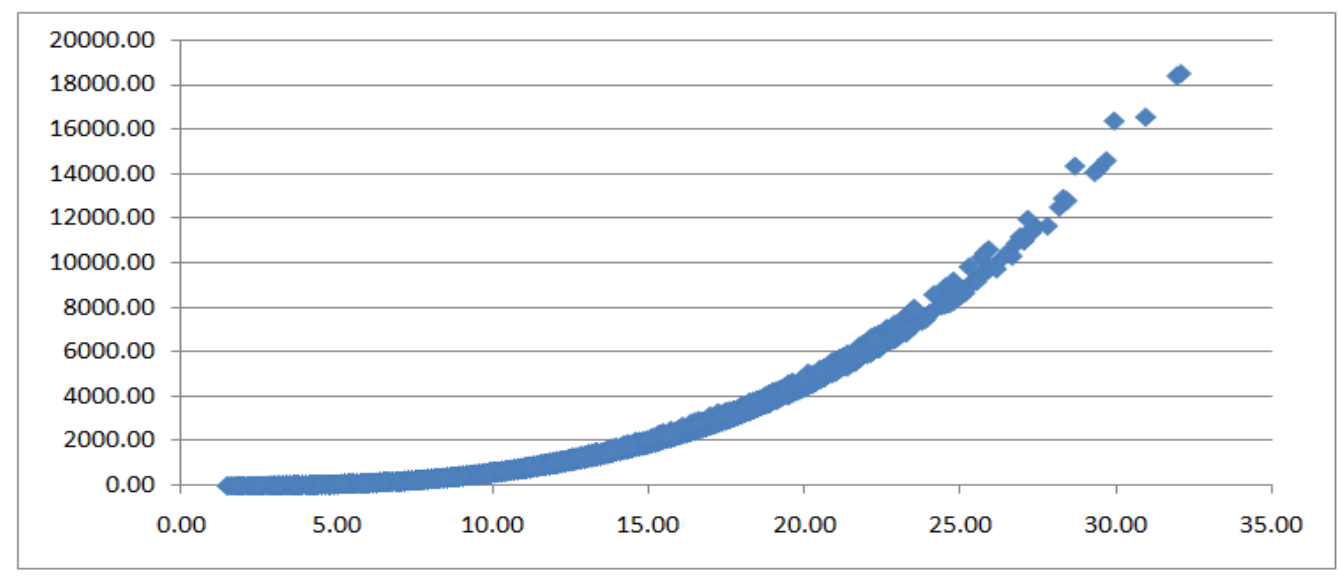

Figure 18: The output power histogram at 50m altitude in Bubian Island

\section{Average Power}

The measured values of average output power in the three considered locations are listed in Table 2.

Table 2: average value of output power

\begin{tabular}{|c|c|c|c|}
\hline Highest & Bubian Island & RasSubyah & Jalaliah \\
\hline $\mathbf{3 0} \mathbf{~ m}$ & 671.01 & 755.75 & 1159.12 \\
\hline $\mathbf{5 0} \mathbf{~ m}$ & 833.34 & 940.71 & 1439.55 \\
\hline
\end{tabular}

Figure 19 shows the average value of power plotted for the three selected locations. The highest average of output power was obtained in jaliah locatiob at 30 as well as $50 \mathrm{~m}$ altitudes.

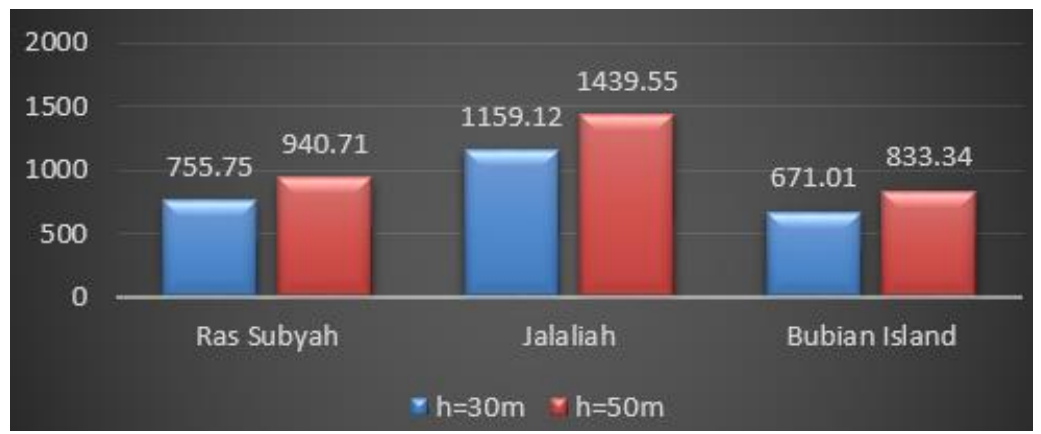

Figure 19: The output power graph for the three situations

\section{Assessment of Wind Turbine Characteristics for the Proposed Locations}

The impact of height in value of the wind power density and the distribution of wind speed are defined in this paper. Where the speed of wind is increase with increasing the height affecting the maximum amount of generated wind energy, at all wind speeds. Also, the 
wind turbine systems' designers need to evaluate the power properties of the wind turbines in order to choose the most efficient turbine system. The value of availability factor, which is used in the most effective wind turbine is in range of $(0.95-0.99)$ that is known as a benchmark factors. The second property is the capacity factor that should be in range of $(0.25-0.40)$. There are many companies that manufacture the commercial types of wind turbine in the market for instance; Mitsubishi, Nordex, as well as Siemens. These types can be evaluated based on their features such as; rated output power, speed of wind, cut-out speeds, cut-in speeds, in addition to efficiency of wind turbine. Table in (appendix A) illustrates some of the operational characteristics of wind turbine models in addition to the required specifications of design.

Equations (5) is utilized to evaluate the efficiency of proposed wind turbines, which can be used to operate the models that are in range of $(0.15-0.50)$. The selected turbine should be operate effectively at average wind speeds of $(716 \mathrm{~m} / \mathrm{s}-16 \mathrm{~m} / \mathrm{s})$.

\section{Wind Turbine Performance}

The capacity factors $\left(\mathrm{C}_{\mathrm{F}}\right)$ for the diverse turbines are approximately within the range within $0.11-0.20$, which make JalAliyah location to be the best suggestion model to be employed. However, the model of SWT-6.0-120 has the best value of efficiency and can provide approximately $6000 \mathrm{~kW}$. Also, the performance coefficient that is denoted by $(\mathrm{Cp})$ is measured through Figure 20 at tip speed equal to (5.044).

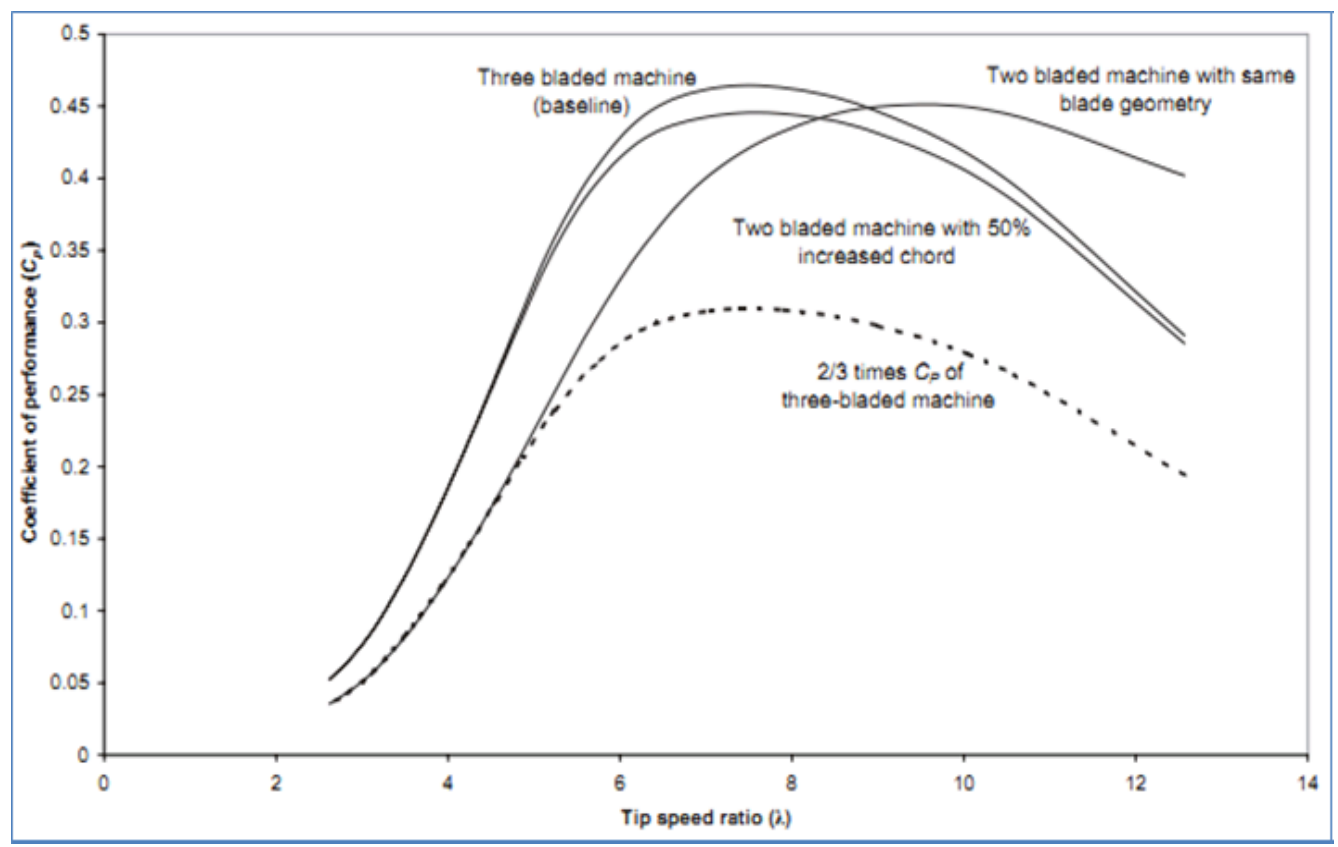

Figure 20: The performance coefficient (Cp) Vs. Tip speed $(\lambda)(T$. Burton, 1947).

Furthermore, the power that can be created using wind turbine farm is equal to $125 \mathrm{MWh}$. The needed wind turbines number (SWT-6.0-120) $=21$ turbines. The third place position is illustrated in Figure 21. There is an extra characteristic could be taken in consideration when choosing the site of wind turbine, like; the wildlife. The chosen site was in $12 \mathrm{~km}^{2}$. 


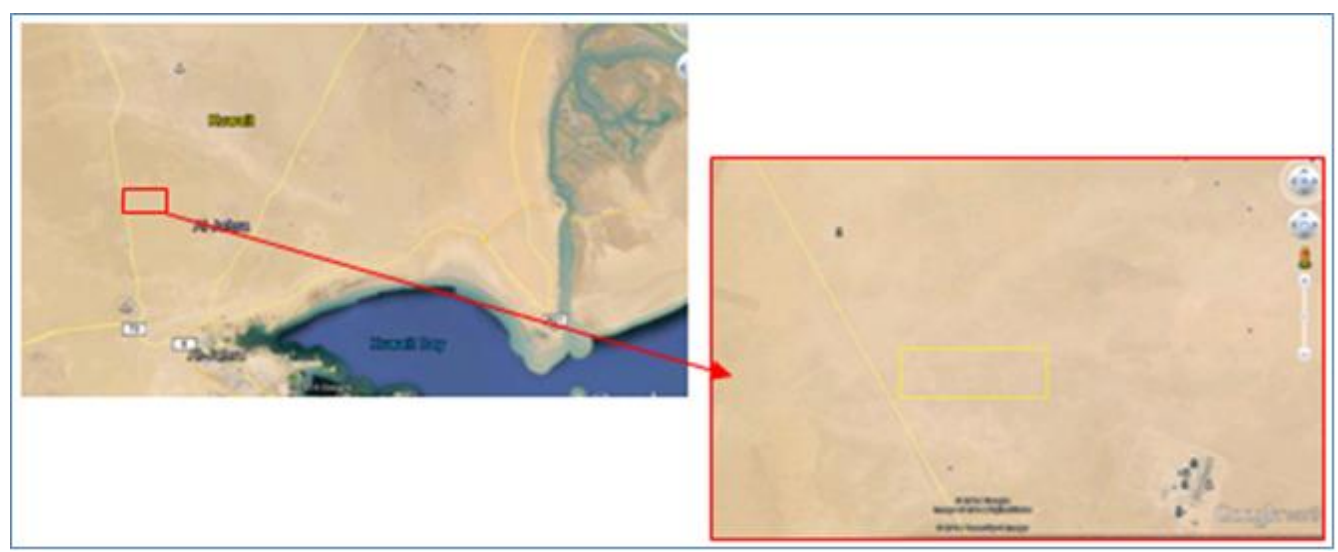

Figure 21: The different locations power

The selected site is near the highway road to ease the transportation. Furthermore, this area should be separated to grids as shown in Figure 22. The wind turbines is dispersed beside three rows, the rotor diameter $=120 \mathrm{~m}$. Therefore, the obtained distance between wind turbines is $600 \mathrm{~m}$ vertically and horizontally. The free region is significant since supplies space for building the service buildings, such as; management, batteries, electrical transformers and maintenance buildings.

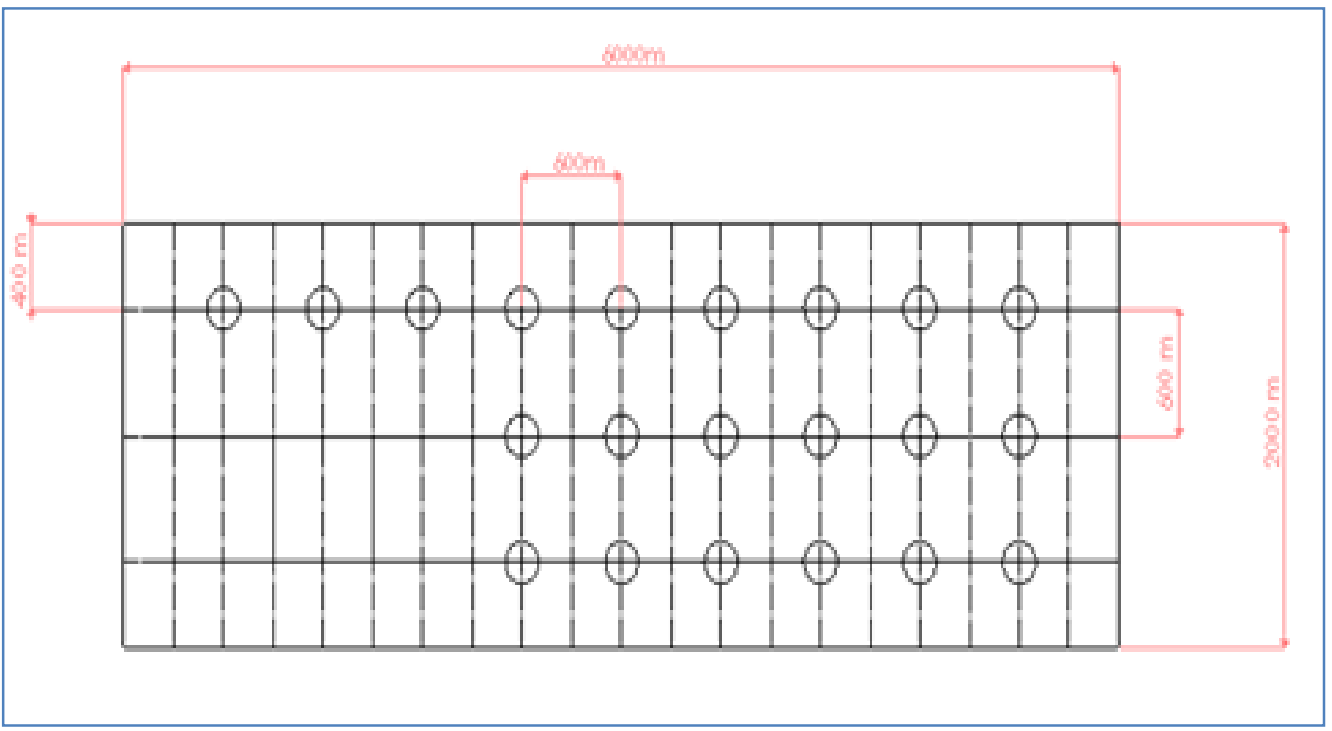

Figure 22 : the grid of wind turbine

\section{Wind Turbine Description}

There are several types of wind turbines. But, in this paper Endasa type is selected with diameter of rotor is equal to $52 \mathrm{~m}$, and also rotor sweep is around $2123 \mathrm{~m}^{2}$, as well as rated value of output power is approximately equal to $800 \mathrm{~kW}$. The diameter of the rotor of the chosen model in this paper is equal to $52 \mathrm{~m}$, and the model has been drawn via solid works software, and exported later to ANSYS as illustrated in Figure 23. A CFD simulation has been employed, and then the geometry has been imported for creating one solid body. 


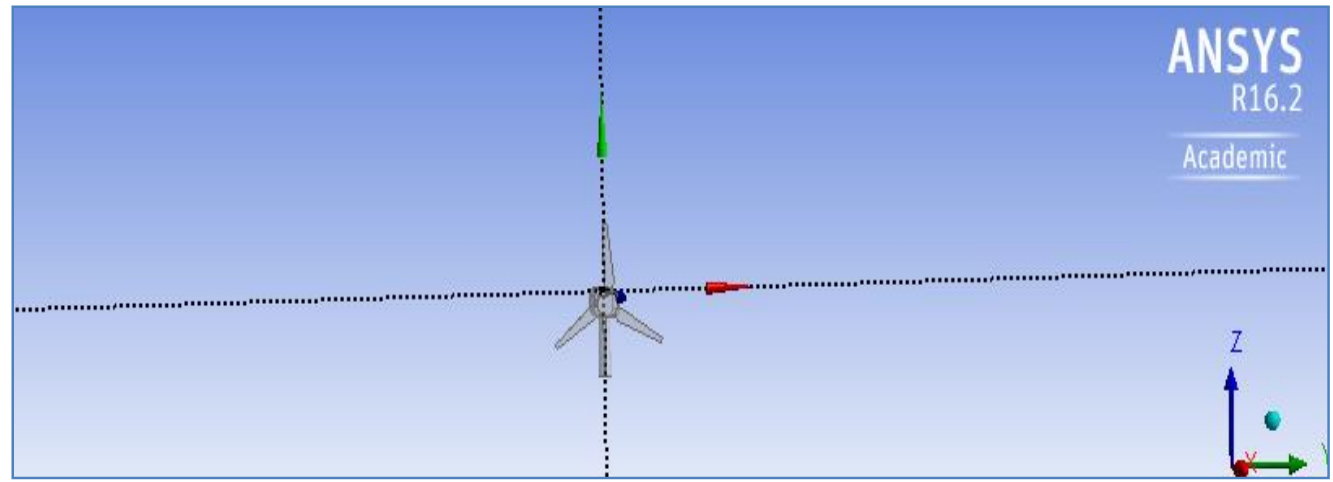

Figure 23: the model of the rotor in ANSYS

As illustrated in Figure 24, a box enclosure has been drawn for defining conditions of the boundary.

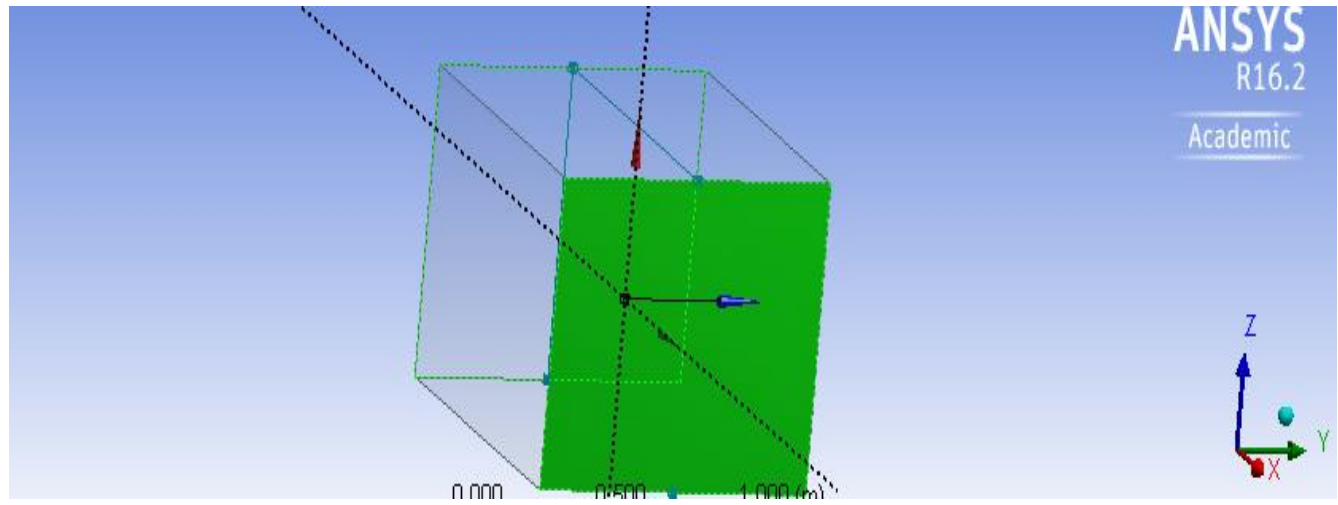

Figure 24: boundary conditions

Analysis of finite element is used to analyze the proposed system through meshing system using mesh toolbox with 32K nodes as illustrated in Figure 25.

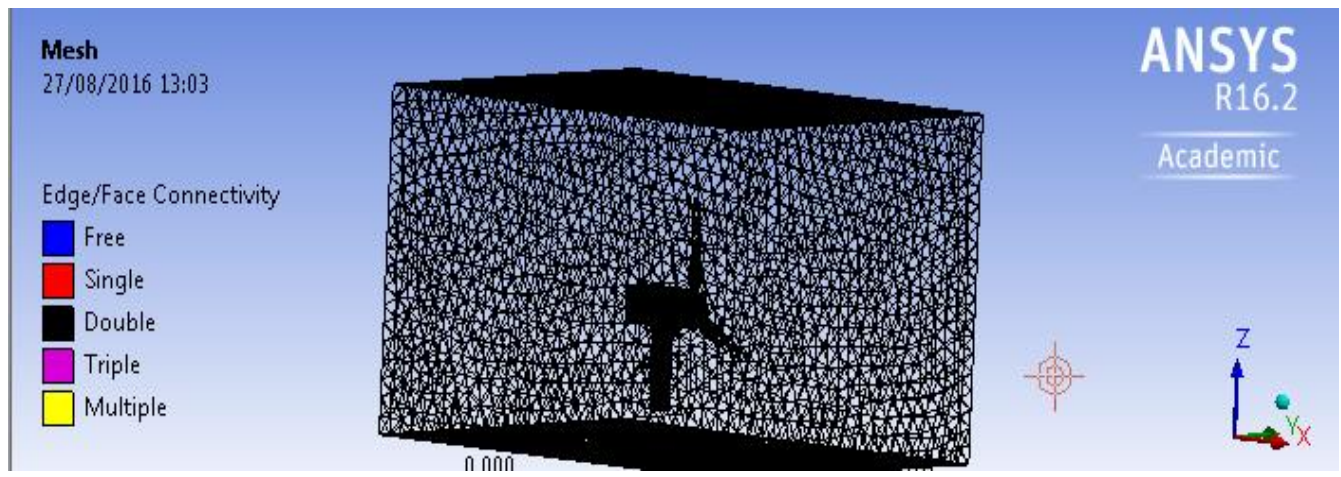

Figure 25: Mesh analysis for model

Then, the model has been imported to the FLUENT in order to observe the distribution of velocity. 


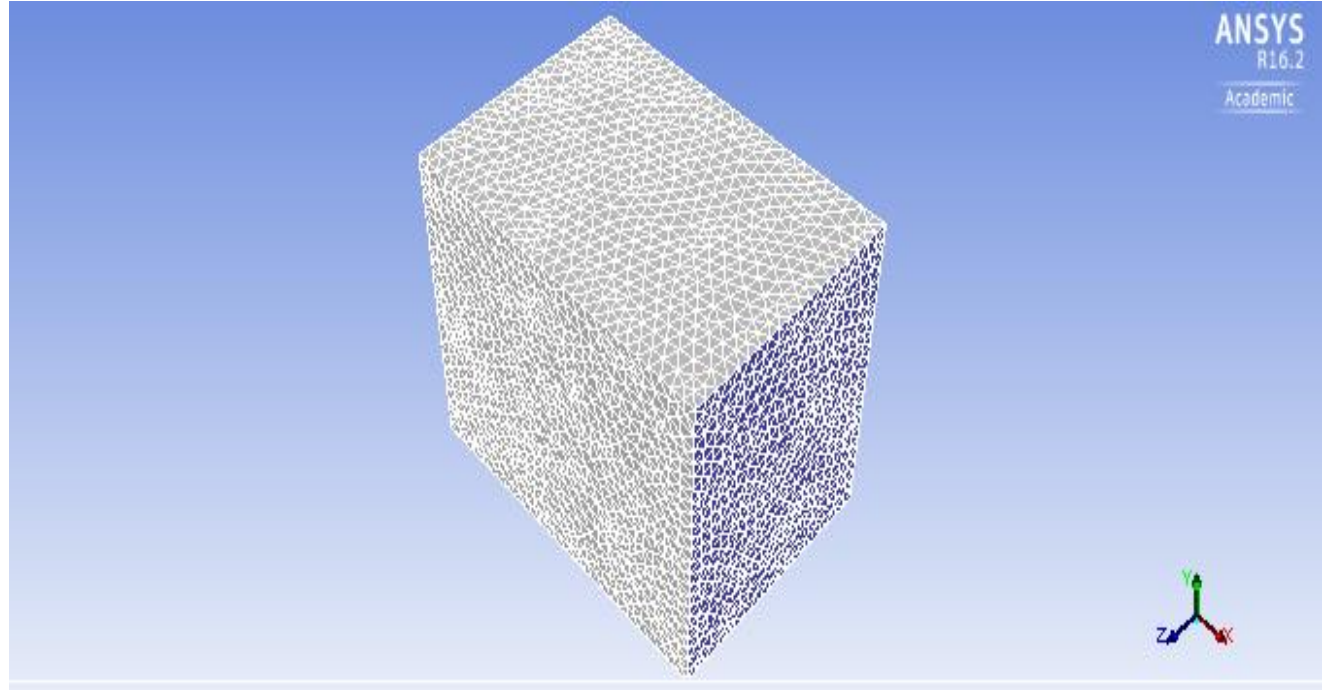

Figure 26: k-epslon model

The inlet velocity of Jal Aliyah is equal to $11.21 \mathrm{~m} / \mathrm{s}$, and number of iterations is equal to 300 iterations. Figure 27 demonstrates the velocity distribution.

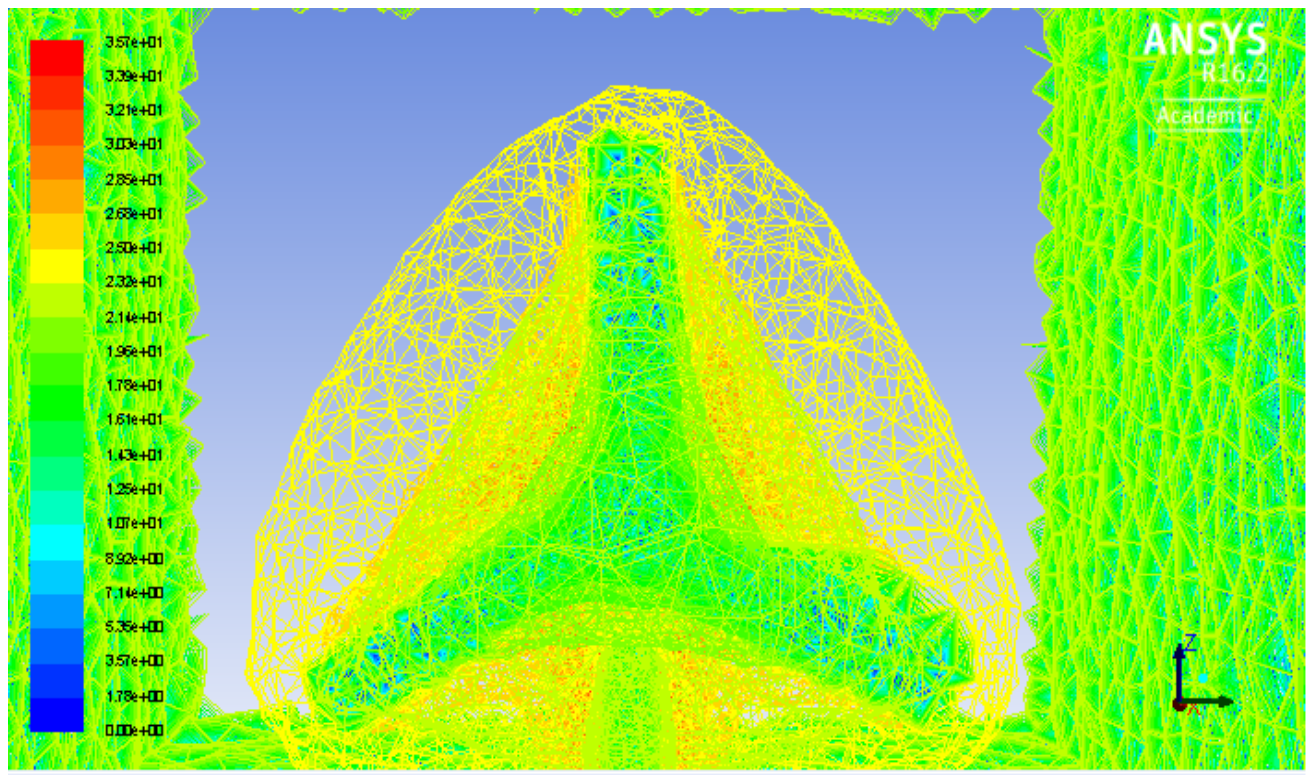

Figure 27: Distribution of the Velocity

As illustrated in Figure 28, the speed of tip is equal to $37 \mathrm{~m} / \mathrm{s}$ in case of the speed of inlet is equal to $11.21 \mathrm{~m} / \mathrm{s}$. Thus, the TSR value is (3.3) and Cp value is (0.14). 


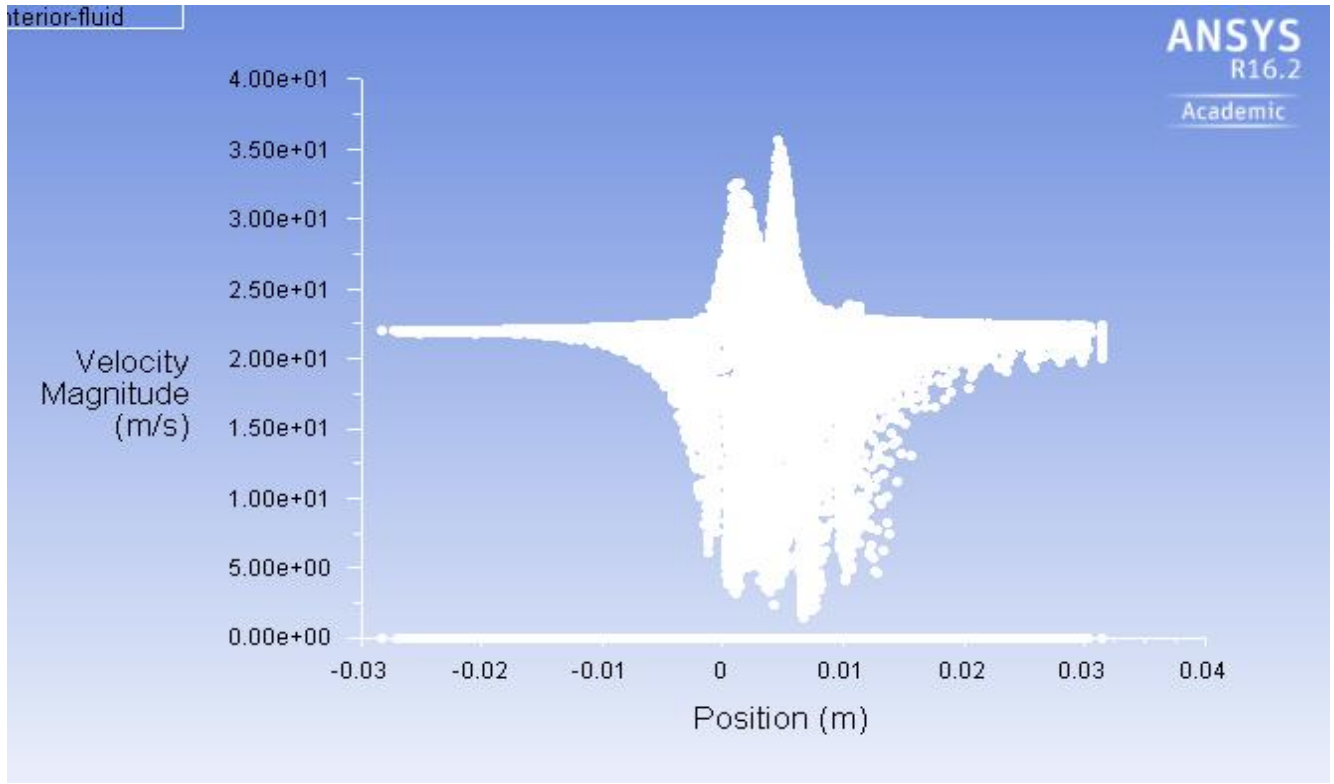

Figure 28: plot of velocity at the tip of blade

Figure 29 shows the expected hourly production of the selected farm, where the annual production is $105082 \mathrm{MW}$. According to (ministry of electricity and water of Kuwait, 2017) the price of the electrical power production per $\mathrm{kWh}$ is $\$ 0.13$. But, $\$ 13.66 \mathrm{~m}$ is required to produce this amount of power using firing fuel.

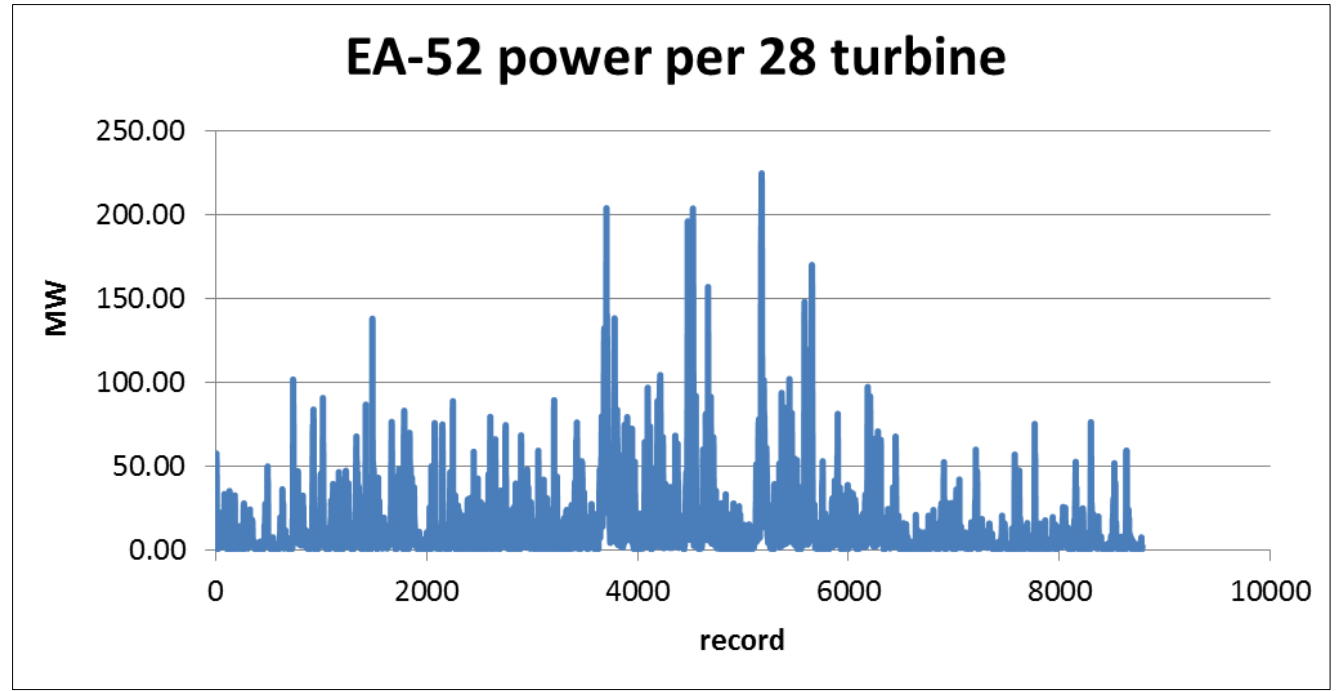

Figure 29: Hourly production of the proposed farm

Installing the wind turbines required $\$ 4000$ per KW (irena, 2012). So, the cost of installing these turbines is $\$ 89.6$, and the operating cost is $\$ 0.05 /$ turbine thus the operating cost for 28 turbines is $\$ 5.2$ Figure 30 illustrates the return rate for the proposed design, which is equal 12 years. 


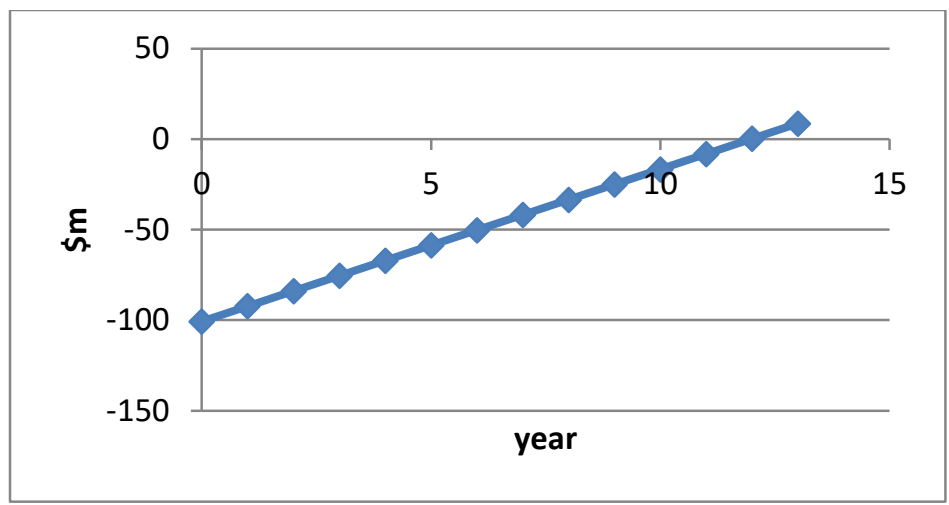

Figure 30: the rate of return for the proposed design

\section{CONCLUSION}

This paper is an evaluation for the renewable via using GCC. The composed meteorological data were employed in estimating the wind energy characteristics for the three considered situations in Kuwait city, which are; Jal Aliyah, RasSubiyah and Bubian Island. The wind standard characteristics are the standard deviation, wind density, highest amount of obtainable energy and the average of highest wind speed. Different studies have been performed in this paper in order to analyze the impact of height on the parameters of wind energy, wind density, in addition to wind speed. Jal Aliyah location has been studied in this paper and the results shown that there is a proportional relation between the wind speed and power, where the maximum power is potential if the speed is equal to $29.1 \mathrm{~m} / \mathrm{s}$, and the maximum averaged flux of wind power is equal to $725.54 \mathrm{~W} / \mathrm{m} 2$. Where both Bubidan Island and Ras Subiyah showed the wind direction in the North-East quadrant with speed is greater than $10 \mathrm{~m} / \mathrm{s}$. But, higher polarized distribution of Jal Aliyah was in the north direction. SWT-6.0-120 type of turbine was chosen with power output equal to 6MWh. JalAliyah location was the optimal selection with 21 turbines and 126 MWh capacity.

\section{REFERENCES}

Abdel Halim A., Salehy and Eskander M. N., Sub-Synchronous Range of Operation for a Wind Driven Double-Fed Induction Generator, Journal of power Electronics, 10(1), 2010.

Al-Karaghouli A., Current Status of Renewable Energies in the Middle East - North African Region, UNEP, 2007.

Al-Mashakbeh, Feasibility Study of Using Wind Turbines with Diesel Generators Operating at One of the Rural Sites in Jordan, Journal of Theoretical and Applied Information Technology, 30 (2), 2011. Available at: http:/ / www.jatit.org/volumes/Vol30No2/6Vol30No2.pdf

Az-Zour North IWPP Project, Partnerships Technical Bureau, available at: http:/ / www.ptb.gov.kw/Admin/DynamicFile.aspx?PHName=DownloadFile\&PageID=4046\& Published=1, Accessed in $25^{\text {th }}$ sep 2018.

Bai C. J., Hsiao F. B., Code Development for Predicting the Aerodynamic Performance of a HAWT Blade with Variable-Speed Operation and Verification by Numerical Simulation, 17nd National Computational Fluid Dynamics (CFD) Conference, 2010.

Bai C. J., Hsiao F. B., Li M. H., Huang G. Y., Chen Y. J., Design of 10 kW Horizontal-Axis Wind Turbine (HAWT) Blade and Aerodynamic Investigation Using Numerical Simulation, National Cheng Kung University, 2013. 
Barlas T. K., and Kuik G. A., Review of state of the art in smart rotor control research for wind turbines, Prog. Aerosp. Sci, 2010.

BNEF, BNEF Statistics, Bloomberg New Energy Finance, 2015.

Burton T., Wind Energy Handbook, Chichester, 2013.

Casini M., Small Vertical Axis Wind Turbines for Energy Efficiency of Buildings, Journal of Clean Energy Technologies, 4(1), 2016.

El-Katiri L., and Husain M., Prospects for Renewable Energy in GCC States: Opportunities and the Need for Reform, the Oxford Institute for Energy Studies, 2014.

EPIA, Un-LOCKING THE Sunbelt Potential of Photovoltaics, European Photovoltaic Industry Association, 2010.

GWEC, Global Wind Energy statistics, 2013, [Online], available at: http://www.gwec.net/wpcontent/uploads/2014/02/GWEC-PRstats-2013_EN.pdf, Accessed in $15^{\text {th }}$ sep. 2018.

MASDAR, Masdar special projects: Dhofar wind farm - Oman, Masdar, 2015.

Moh M., Saad M., and Asmuin N., Comparison of Horizontal Axis Wind Turbines and Vertical Axis Wind Turbines, Journal of Engineering, 4(8), 2014.

NBAD. PwC and University of Cambridge, Financing the Future of Energy, National Bank of Abu Dhabi, 2015.

Wang P., Aerodynamic Shape Optimization of a Vertical-Axis Wind Turbine Using Differential Evolution, International Scholarly Research Network, 2015.

Wiser R., and Yang Zh., Wind Energy, Cambridge University Press, 2011. 